\title{
Tocilizumab (TCZ) may be an effective treatment for poly-juvenile idiopathic arthritis ( $p$ JIA) as for rheumatoid arthritis (RA)
}

\author{
Ken-ichi Yamaguchi² ${ }^{*}$, Mitsumasa Kishimoto', Masato Okada² \\ From 2011 Pediatric Rheumatology Symposium sponsored by the American College of Rheumatology \\ Miami, FL, USA. 2-5 June 2011
}

\section{Purpose}

TNF inhibitors are established treatment for poly-juvenile idiopathic arthritis (pJIA), but there are needs of alternative therapy for refractory patients. Tocilizumab (TCZ) has been widely used for rheumatoid arthritis (RA) in adults, and the effectiveness for systemic JIA has been well-documented. However, the experience on pIIA is limited. We compared the clinical courses of our patients of RA and PJIA to estimate the effectiveness of TCZ.

\section{Methods}

We retrospectively reviewed clinical finding and assessed disease activity index-CRP (DAS-CRP) of four adults with RA and one child with pJIA. Three of four RA are pretreated patients by other biological agents (Infliximab, Adalimumab, Etanercept) and TCZ was first biological agent for one RA and pJIA patients. All patients had significant disease activity (High 4, Moderate 1) when TCZ were administered.

\section{Results}

Three of four RA and a pJIA patients are met the remission criteria of DAS-CRP after 28 weeks administration of TCZ. Another RA patient showed improvement (DAS-CRP $5.19 \rightarrow 3.65$ ). There was no apparent side effect in any of the patient.

\section{Conclusion}

In this small series, TCZ provided benefit to all of five patients (RA 4, pJIA 1). In the Post Marketing Surveillance of pediatric case of TCZ (132 cases) in Japan,

${ }^{2}$ St. Luke's International Hospital, Tokyo, Japan

Full list of author information is available at the end of the article
TCZ showed high effectiveness (Remarkable effective $53.0 \%$, Effective $42.4 \%$ ) and safety in pJIA. TCZ may be a good option to treat not only sJIA but also pJIA.

\section{Disclosure}

Ken-ichi Yamaguchi: None; Mitsumasa Kishimoto: None; Masato Okada: None.

\section{Author details}

'St Luke's International Hospital, Chuo-ku, Tokyo, Japan. ${ }^{2}$ St. Luke's International Hospital, Tokyo, Japan.

Published: 13 July 2012

\section{doi:10.1186/1546-0096-10-S1-A55}

Cite this article as: Yamaguchi et al:: Tocilizumab (TCZ) may be an effective treatment for poly-juvenile idiopathic arthritis ( $p J \mid A)$ as for rheumatoid arthritis (RA). Pediatric Rheumatology 2012 10(Suppl 1):A55.
Submit your next manuscript to BioMed Central and take full advantage of:

- Convenient online submission

- Thorough peer review

- No space constraints or color figure charges

- Immediate publication on acceptance

- Inclusion in PubMed, CAS, Scopus and Google Scholar

- Research which is freely available for redistribution
C Biomed Central

\section{(Ciomed Central}

